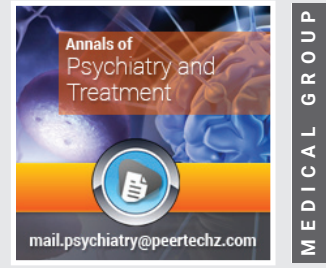

\title{
Alien Abduction Experience: Definition, neurobiological profiles, clinical contexts and therapeutic approaches
}

Received: 04 April, 2020

Accepted: 03 June, 2020

Published: 04 June, 2020

*Corresponding author: Dr. Giulio Perrotta, Psychologist sp.ing in psychotherapy with a strategic approach, Forensic Criminologist expert in sectarian cults, esoteric and security profiles, Jurist sp.ed SSPL, Lecturer, Essayist, Italy, E-mail: giuliosr1984@hotmail.it

https://www.peertechz.com

Check for updates

\section{Giulio Perrotta*}

Psychologist sp.ing in psychotherapy with a strategic approach, Forensic Criminologist expert in

sectarian cults, esoteric and security profiles, Jurist sp.ed SSPL, Lecturer, Essayist, Italy

\begin{abstract}
Starting from the general concept of "alien abduction experience", the present work focuses on the essential aspects of the disorder defining the clinical and diagnostic contexts, laying the foundations for correct differential diagnosis, without neglecting the neural characteristics elaborated in the scientific community. The discussion concludes with the best therapeutic approaches suggested on the subject, paying particular attention to analyzing the related profiles and those related to the presumed discovery of alien implants in the human body of patients.
\end{abstract}

\section{Introduction and definition}

The experience of alien abduction consists in the alleged kidnapping of human beings by extraterrestrial biological entities, by means of superior technologies. The information is not always clear whether these experiences are lived on board spacecraft orbiting deep space outside the Earth's orbit or inside specially built underground military bases. The narratives supporting this circumstance are often different, as are the medical investigations that are carried out by an unspecified specialized technical staff [1].

In the world, thousands are people who claim to have lived on their own skin, at least once, the experience of being kidnapped by an alien race (mainly described as gray type humanoids, Nordic type humanoids and reptiloids). Certainly it is the fact that to talk about alien abductions we must obviously give the existence of extraterrestrial biological entities capable of interacting with us and possessing highly advanced intelligence and technology, far superior to our currently known. The (non-scientific) evidence supporting the confirmation hypothesis of the phenomenon are eyewitness testimony, mechanical evidence (audio and video), the retrieval of objects related to the "abduction" phenomenon such as the plants allegedly found in the body of the kidnapped and the experiences of direct contact with one of the alien breeds described [1].

On the basis of these premises, the "Close Encounter", according to the classification of the astrophysicist Hynek, subsequently revisited by the UFO community according to Bloecher's directives, can be of seven types: [1].

a) in the meeting of type I (CE1), one or more flying objects of defined solid mass or stray lights are sighted;

b) in the meeting of the II type (CE2), there are phenomena caused by the presence of the flying object, such as the Crop Circles, the heat or radiation that damages the ground, human paralysis not otherwise diagnosed, interference with engines or radio-television reception and the loss of space-time cognition (intended as a flaw in the memory of a person associated with the alien encounter);

c) in the meeting of the III type (CE3) animated beings are seen, understood as extraterrestrial biological entities, in association with a sighting of unidentified flying objects; 
d) in the meeting of the IV type (CE4), one witnesses or is the victim of an alien abduction;

e) in the meeting of the Vtype (CE5) there is a direct encounter with the extraterrestrial creature in a bilateral communication relationship established through conscious, voluntary and active human initiatives, or in any case through psychic cooperative communication;

f) in the meeting of the VI type (CE6) long-term pathological effects are suffered, deriving from direct contact with the alien creature. Vallée and Naisbitt, two worldrenowned ufologists, describe this type of encounter as redundant, as the Hynek scale itself (the original one) describes the II type as "a UFO encounter that leaves traces or direct and obvious physical evidence of any kind";

g) in the meeting of the VII type (CE7), there is finally the direct participation, the human-alien hybridization through mating or the birth of a creature that is the fusion with the terrestrial race.

The phenomenon in question is therefore called "Close encounter of the fourth type" and has been described by those who claim to have lived it as an often invasive and traumatic experience that has "missing time" as its first narrative element, ie an alleged block of time (never scientifically proven), called by insiders also "alien interference" [2]. This memory would seem removed on a conscious level but not on an unconscious level, as if the mechanism of removal by the psychological instance of the Ego was triggered; however, to date there is no scientific evidence to support this hypothesis and there is also a lack of robust evidence of any kidnappings aboard spacecraft [3,4]. The stories of the kidnappings are therefore essentially based on the testimonies of the "kidnapped" and even if some ufology scholars claim that these memories can be reported on a conscious level through hypnosis, neurolinguistic programming and graphological analysis, the scientific evidence to support the truthfulness and correctness of these episodes, often altered or confused by false memories capable of reconstructing events that never happened [5,6]. This temporal void is instead described in psychiatric clinic as a typical element in traumatic experiences and dissociations [7-11].

Despite the suggestiveness of the narratives, even of events of international impact such as those of Raymond W. Bernard, of the spouses Hill, Travis Walton and Pier Fortunato Zanfretta, there is no scientific evidence of the existence of such circumstances [1].

In Italy, in the last decade, a well-known university professor and independent researcher has published numerous investigations on the subject of hypnosis and alien abductions, claiming to have analyzed thousands of cases and to be able to demonstrate the veracity of the phenomenon $[12,13]$, however, publicly, it never provided detailed research data and the final studies were never examined by a commission of inquiry capable of confirming the reliability and scientificity of the results, exactly as happened for the psychologist's studies Frederick Malmstrom or William Mc Call. To date, there is no scientific publication that can refer to this research so clearly detailed and in-depth [1].

From the phenomenon of alien abduction, that of "contactism" must be differentiated, both from a technical and clinical point of view: the latter is the person who claims to be in contact with alleged extraterrestrial biological entities, in order to receive messages and communications of a nature mysterious, esoteric and spiritual (for the good of humanity), without ever undergoing contact with violence or compulsion [1]. This hypothesis, in a psychiatric clinic, is often associated with delusional or hallucinatory experiences, the result of a psychotic disorder or a class A personality disorder, wellstructured and outlined in their chronic condition, according to DSM-5 [15]. In the hypothesis of alien abduction, if not repeated over time (according to the patient's medical history), one could think of episodes of an acute or in any case less serious and pervasive nature, such as, for example, episodes of sleep paralysis, epilepsies of the temporal lobe, alterations determined by modifications of the electromagnetic field, constructions of false memories on a post-traumatic basis or single psychotic episode and dissociative tendency [16-33]. The DSM-IV, in its revised version $\mathrm{R}$, included alien abductions in the section dedicated to religious and spiritual problems (V62.89) supporting the direct connection with the last generation religious movements. The DSM- 5 instead radically shifts the axis of investigation by eliminating the thorny issue, thus bringing into play the multifactorial diagnosis and the possible correlations with the pre-existing conditions already categorized in the manual [5]. In other cases, on the other hand, the hypotheses of voluntary mystifications have often been found, as happened in the cases of the contactists Adamski, Manzano and Meier [1].

Psychologist Chris French examined nineteen people who believed they were abducted by aliens and found a tendency towards fantasy, hallucinations, dissociation and belief in paranormal greater than normal, concluding that there is no reason to believe that those people are victims of kidnappings by extraterrestrial biological entities [34].

Finally, in some episodes of kidnappings, surgical interventions aimed at implanting alien devices in the human body are often mentioned, for the remote control of thoughts and physiological functions. Such "alien" plants would be concrete proof of the existence of the phenomenon [14]. However, despite some researchers and exponents of the scientific world have tried to find the materials explanted by the bodies, such as the well-known findings of Dr. Roger Leir (first known as a surgeon and then as a podiatrist specialized in micro-operations exclusively on the foot) and by ufologist (expert in certified hypnotherapy) Derrel Sims, little more than a dozen physical tests collected and certified (including, in 1978, a mysterious triangular object with a metallic nuclear heart, seven centimeters long and four centimeters long width,

Citation: Perrotta G (2020) Alien Abduction Experience: Definition, neurobiological profiles, clinical contexts and therapeutic approaches. Ann Psychiatry Treatm 
covered by a red-brown membrane and equipped with many receptors connected to the nerve endings), these findings were then mysteriously hidden, effectively avoiding further and accurate technical-scientific and biological investigations [1].

Popularization articles, there is no physical plant (of alleged alien origin) analyzed according to the criteria and methods validated by the international scientific community and reported on articles scientific published in accredited and specialized journals, despite the investigations carried out carried out by approved and accredited laboratories. On this uncertain situation, the suggestive statements of Leir and Sims himself, accompanied by written reports, focused on the following data:

a) The metallic, non-metallic and biological nature of the objects found after explant surgery;

b) The presumed materials, under one centimeter in size, manufactured with metal alloys of a meteoritic nature of the class of hexahedrites, with traces of 11 elements including Cobalt, Iridium, Iron, Nickel and Boron, wrapped in an oily and membranous shell ( hard to the touch, well beyond tempered steel), composed of protein clots, hemoseridine, keratin and nerve proprioceptors, capable of preventing an immune response of an inflammatory nature, and particularly sensitive to phonons -quantum particles associated with the vibrational waves of solids-;

c) some implants emitted a strong electromagnetic field, between 2 and 6 Milligauss (in 15-93 MHz), before surgical removal;

d) explantation causes a neurobiological, emotional and somatic reaction in the patient;

e) the location of the implants under the epidermal surface and near the bones, in the hands, feet and head.

\section{Neurobiological profiles and clinical correlations}

The few scientific studies certified and published in accredited journals reveal, in the current state of knowledge, that:

a) there is no documented evidence in the academic and scientific field about the chemical-physical investigations carried out on the findings extrapolated from humans, although there are suggestive reports from accredited laboratories about the mysterious origin of the same objects, with strong indication for an extraterrestrial origin;

b) patients who report having experienced alien abductions have a greater attraction and interest in paranormal phenomena and have a history of post-traumatic episodes and sleep paralysis (and disturbances), all events capable of generating false memories and episodes hallucinators, as in the hypothesis of postoperative awakening; [35]. c) the strong tendency for patients to dissociate is connected with an altered functionality of the temporal lobes; $[16,40]$.

d) alien abductions, abuses with a satanic background and the identities of past lives seem connected to the reconstruction of false memories, typical in patients with high imagination and fantasy, connected to a hyperactivity of the upper longitudinal fasciculus and an altered functionality of the frontal lobe, of the prefrontal cortical regions, the hippocampals and vascular deficits (in particular, those referring to the anterior artery in the Willis's Polygon), in situations of high stress perceived by the patient [36-39].

\section{Clinical strategies and therapeutic approaches}

The best treatment suggested in the scientific literature is the one combined between psychotherapy (stratetic or cognitive-behavioral) and psychopharmacology (especially in the presence of evident clinical psychotic signs or disorders that need a pharmacological approach to stabilize the patient before continuing or setting up psychotherapy targeted and centered on the needs and needs specifically identified during the anamnesis). In the presence of confirmed dissociative episodes or rich production of false memories, it is not recommended to make use of hypnosis and suggestive techniques, which could incentivize or strengthen this patient's interpretation of reality $[5,10]$

\section{Conclusion}

The phenomenon of "alien abductions" seems to have a clear psychopathological origin. In the absence of definitive evidence, especially in terms of "alien" implants, the conclusions are clearly oriented towards a clinical diagnosis that finds its basis between voluntary mystification for gainful or psychological purposes (for example, the need to attract the attention of borderline and histrionic personalities), posttraumatic stress disorder, dissociative disorder, obsessivecompulsive disorder and / or sleep disturbances associated with personalities with psychotic traits and (in severe cases) psychotic profiles. According to this writer, an evaluation scale is therefore possible on the basis of the symptoms described in the patient's anamnesis:

Level 1: voluntary mystification;

Level 2: delusions or hallucinations determined by the use of substances capable of altering the state of consciousness or by morbid neurological forms (such as, epilepsy, tumors, vasculopathies, vascular disorders, trauma);

Level 3: false memories connected to post-traumatic stressful events, with pathologically oriented personality traits

Level 4: altered state caused by the obsessive idea of abduction, in comorbidity with sleep disturbances and pathologically oriented personality traits;

Citation: Perrotta G (2020) Alien Abduction Experience: Definition, neurobiological profiles, clinical contexts and therapeutic approaches. Ann Psychiatry Treatm 4(1): 025-029. DOI: https://dx.doi.org/10.17352/apt.000016 
Level 5: altered state caused by dissociative disorder;

Level 6: altered state caused by eccentric personality profiles (cluster B, DSM-V);

Level 7: altered state caused by psychotic personality profiles (cluster A, DSM-V).

\section{References}

1. Perrotta G (2017) Criminologia esoterica, Primiceri editore, $2^{\text {th }}$ ed.

2. Malanga C (1998) Gli UFO nella mente. Interferenze aliene. Bompiani, Milano.

3. Perrotta G (2020) Human mechanisms of psychological defence: definition historical and psychodynamic contexts, classifications and clinical profiles. Int J Neurorehabilitation Eng 7: 1, 1000360. Link: https://bit.ly/2yZ3nD0

4. Perrotta G (2019) Psicologia dinamica, Luxco Ed, $1^{\text {st }}$ ed.

5. Perrotta G (2019) Psicologia clinica, Luxco Ed, $1^{\text {st }}$ ed.

6. Perrotta G (2019) Psicologia generale, Luxco Ed, $1^{\text {st }}$ ed,

7. Perrotta G (2019) Post-traumatic stress disorder: Definition, contexts, neura correlations and cognitive-behavioral therapy. J Pub Health Catalog 2: 40-47. Link: https://bit.ly/3eM8buJ

8. Perrotta G (2019) The phenomenon of demoniac possession: definition, contexts and multidisciplinary approaches. J Psychol Mental Health Care. J Psychology Mental Health Care 3: 1-019. Link: https://bit.ly/3dqGFTd

9. Perrotta G (2019) Obsessive-Compulsive Disorder: definition, contexts, neural correlates and clinical strategies. Cientific J Neurol 08-16.

10. Perrotta G (2019) The reality plan and the subjective construction of one's perception: the strategic theoretical model among sensations, perceptions, defence mechanisms, needs, personal constructs, beliefs system, social influences and systematic errors. Journal of Clinical Research and Reports. J Clin Res Reports 1.

11. Perrotta G (2020) Psychological trauma: definition, clinical contexts, neural correlations and therapeutic approaches. Current Research in Psychiatry and Brain Disorders. Curr Res Psychiatry Brain Disord: CRPBD-100006. Link: https://bit.ly/2MouFpg

12. Malanga C, Alieni o Demoni (2010) Terre Sommerse Ed

13. Malanga C (2010) Alien Cicatrix. e-book 1-2.

14. Roger KL (2005) The Aliens and the Scalpel: Scientific Proof of Extra terrestrial Implants in Humans. Book Tree.

15. Irwin H, Schofield M, Baker IS (2014) Dissociative tendencies, sensoryprocessing sensitivity and aberrant salience as predictors of anomalous experiences and paranormal attributions. J Society Psychical Res 78: 193206. Link: https://bit.ly/3gKmQIp

16. French C, Holden KJ (2002) Alien abduction experiences: some clues from neuropsychology and neuropsychiatry. Cognitive Neuropsychiatry 7: 163-178 Link: https://bit.ly/302JMNc

17. Perrotta G (2019) Sleep-wake disorders: Definition, contexts and neural correlations. J Neurol Psychol. 7: 09. Link: https://bit.ly/2ZZwTUb

18. Bartholomew RE, Basterfield K, Howard GS (1991) UFO abductees and contactees: Psychopathology or fantasy proneness? Professional Psychology: Research and Practice 22: 215-222. Link: https://bit.ly/3cts1sW

19. Cheyne JA (2001) The ominous numinous: Sensed presence and 'other' hallucinations. J Consciousnes Studies 8: 133-150. Link: https://bit.ly/2U43691

20. Cheyne JA, Newby-Clark IR, Rueffer SD (1999) Sleep paralysis and associated hypnagogi c and hypnopompi c experiences. J Sleep Res 8: 313-318.

21. Hobson JA, McCarley RW (1997) The brain as a dream state generator: An activationsynthesis hypothesi s of the dream process. Am J Psychiatry 134 1335-1348. Link: https://bit.ly/301huCY

22. Newman LS, Baumeister RF (1996) Toward an explanation of the UFO abduction phenomenon: Hypnotic elaboration, extraterrestrial sadomasochism, and spurious memories. Psychological Inquiry 7: 99-126. Link: https://bit.ly/3cmHqeB

23. Persinger MA, Makarec K (1987) Temporal lobe epileptic signs and correlative behaviors displayed by normal populations. J General Psychol 114: 179-195. Link: https://bit.ly/2zJVjGH

24. Persinger MA, Tiller SG, Koren SA (2000) Experimental simulation of a haunt experience and elicitation of paroxysmal electroencephalographi $c$ activity by transcerebral complex magnetic fields: Induction of a synthetic 'ghost'? Perceptual and Motor Skills 90: 659-674. Link: https://bit.ly/36UwR1I

25. Persinger MA, Valliant PM (1985) Temporal lobe signs and reports of subjective paranormal experiences in a normal population. Perceptual and Motor Skills 60: 903-909. Link: https://bit.ly/2ZZpXq5

26. Powers SM (1994) Dissociation in alleged extraterrestrial abductees Dissociation 7: 44-50. Link: https://bit.ly/2Xn0xkq

27. Guberman A, Simpson C (1983) Sexual ictal manifestations predominate in women with temporal lobe epilepsy: a finding suggesting sexual dimorphism in the human brain. Neurology 33: 323-330. Link: https://bit.ly/2XQWw74

28. Ring K, Rosing CJ (1990) The Omega Project: A psychologica I survey of persons reporting abductions and other UFO encounters. J UFO Studies 2 $59-98$

29. Rodeghier M, Goodpaster J, Blatterbauer S (1991) Psychosocial characteristics of abductees: Results from the CUFOS abduction project. J UFO Studies. 3 : $59-90$

30. Schacter DL, Reiman E, Curran T, Yun LS, Bandy D, et al. (1996) Neuroanatomica I correlates of veridical and illusory recognition memory: Evidence from positron emission tomography. Neuron 17: 267-274. Link: https://bit.ly/3dqWdpP

31. Symons D (1993) The stuff that dreams aren't made of: Why wake-state and dream-state sensory experiences differ. Cognition 47: 181-217. Link: https://bit.ly/306heC

32. Terrillon JC, Marques-Bonham S (2001) Does recurrent isolated sleep paralysis involve more than cognitive neurosciences? Journal of Scientific Explanation 15: 97-123. Link: https://bit.ly/2AzMSOI

33. Twemlow SW, Gabbard GO, Jones FC (1982) The out-of-body experience: A phenomenologica I typology based on questionnaire responses. Am J Psychiatry 139: 450-455. Link: https://bit.ly/3eNJEpb

34. French C (2008) Psychological aspects of the alien contact experience. Cortex 44: 1387-1395. Link: https://bit.ly/2BimgkW

35. Forrest DV (2008) Alien abduction: a medical hypothesis. J Am Acad Psychoanal Dyn Psychiatry 36: 431-442. Link: https://bit.ly/2zWu0sH

36. Spanos NP, BurgessCA, Burgess MF (1994) Past-life identities, UFO abductions, and satanic ritual abuse: the social construction of memories. Int J Clin Exp Hypn. 42: 433-446. Link: https://bit.ly/2U1y7dP

Citation: Perrotta G (2020) Alien Abduction Experience: Definition, neurobiological profiles, clinical contexts and therapeutic approaches. Ann Psychiatry Treatm 4(1): 025-029. DOI: https://dx.doi.org/10.17352/apt.000016 
37. O'Mara S (2009) Torturing the brain. Trend in Cognitive Sciences 13: 497-500. Link: https://bit.ly/3dq0ERP

38. McNally RJ, Lasko NB, Clancy SA, Macklin ML, Pitman RK. et al. (2004) Psychophysiological responding during script-driven imagery in people reporting abduction by space aliens. Psychol Sci 15: 493-497. Link: https://bit.ly/3eF5VFt
39. Appelle S, Lynn SJ, Newman LS (2012) Alien abduction experiences. Research Gate. Link: https://bit.ly/2ZWLLTj

40. Paley J (2007) Satanic abuse and alien abduction: a comparative analysis theorizing temporal lobe activity as a possible connection between anomaloous memories. Bri J Social Work 27: 43-70. Link: https://bit.ly/301Ipyu

Discover a bigger Impact and Visibility of your article publication with

Peertechz Publications

\section{Highlights}

* Signatory publisher of ORCID

* Signatory Publisher of DORA (San Francisco Declaration on Research Assessment)

* Articles archived in worlds' renowned service providers such as Portico, CNKI, AGRIS, TDNet, Base (Bielefeld University Library), CrossRef, Scilit, J-Gate etc.

* Journals indexed in ICMJE, SHERPA/ROMEO, Google Scholar etc.

* OAI-PMH (Open Archives Initiative Protocol for Metadata Harvesting)

- Dedicated Editorial Board for every journal

* Accurate and rapid peer-review process

- Increased citations of published articles through promotions

* Reduced timeline for article publication

\section{Submit your articles and experience a new surge in publication services}

(https://www.peertechz.com/submission).

Peertechz journals wishes everlasting success in your every endeavours.

Copyright: @ 2020 Perrotta G. This is an open-access article distributed under the terms of the Creative Commons Attribution License, which permits unrestricted use distribution, and reproduction in any medium, provided the original author and source are credited.

Citation: Perrotta G (2020) Alien Abduction Experience: Definition, neurobiological profiles, clinical contexts and therapeutic approaches. Ann Psychiatry Treatm 4(1): 025-029. DOI: https://dx.doi.org/10.17352/apt.000016 